\title{
Kajtún, un nuevo sitio maya con monumentos esculpidos en la región Río Bec
}

Philippe Nondédéo y Alfonso Lacadena

\section{(2) OpenEdition}

\section{Journals}

Edición electrónica

URL: https://journals.openedition.org/jsa/2612

DOI: $10.4000 /$ jsa. 2612

ISSN: 1957-7842

Editor

Société des américanistes

\section{Edición impresa}

Fecha de publicación: 5 enero 2004

Paginación: 183-201

ISSN: 0037-9174

\section{Referencia electrónica}

Philippe Nondédéo y Alfonso Lacadena, «Kajtún, un nuevo sitio maya con monumentos esculpidos en la región Río Bec», Journal de la Société des américanistes [En línea], 90-1 | 2004, Publicado el 05 enero 2009, consultado el 04 septiembre 2022. URL: http://journals.openedition.org/jsa/2612 ; DOI: https://doi.org/10.4000/jsa.2612 


\title{
KAJTÚN, UN NUEVO SITIO MAYA CON MONUMENTOS ESCULPIDOS EN LA REGIÓN RÍO BEC
}

\author{
Philippe NONDÉDÉO * y Alfonso LACADENA **
}

El sitio maya de Kajtún se localiza en el sureste del Estado de Campeche, a $3.5 \mathrm{~km}$ al noreste del Grupo B de Río Bec (Figura 1). Fue descubierto en abril de 2002 en el marco del Proyecto Río Bec por medio de brechas de exploración conducidas por $\mathrm{P}$. Nondédéo en un sector restringido de la periferia de Río Bec ${ }^{1}$. En 2003, efectuamos el levantamiento y la descripción de las principales estructuras del sitio mientras que el epigrafista $\mathrm{A}$. Lacadena se encargó del rescate de la información epigráfica legible en las siete estelas halladas el año anterior. Finalmente, en 2004, realizamos una serie de sondeos estratigráficos en las principales plazas y patios con el fin de establecer una secuencia general de la ocupación ${ }^{2}$.

El interés de Kajtún no reside solamente en la presencia de estelas con inscripciones glíficas - un rasgo poco frecuente en la tradición cultural Río $\mathrm{Bec}^{3}$-, sino también en la fuerte densidad de edificios que constituyen su núcleo, los cuales definen un patrón de asentamiento centralizado atípico en esta región. En efecto, los sitios de la provincia estilística Río Bec se caracterizan generalmente por un patrón muy disperso, sin lugar central, y se componen de pequeños grupos arquitectónicos, a veces aislados unos de otros (Nondédéo 2003, pp. 8185). Además de su organización espacial nucleada, poco común en la región, Kajtún es también llamativo por la cualidad de sus edificios donde destaca la ausencia de edificios con cuartos múltiples, representativos de la región. En cambio, se observan basamentos piramidales característicos de la tradición Petén así como distintos tipos de edificios alargados, poco presentes en el sector Río Bec.

\section{Contexto del descubrimiento}

El hallazgo de Kajtún se hizo dentro de un trabajo de prospección arqueológica de gran amplitud que se desarrolló en 2003 en la periferia de los grupos

* UMR 8096 du CNRS, Maison de l'archéologie et de l'ethnologie, Nanterre [philippe. nondedeo@yahoo.com].

** Universidad Complutense, Madrid [lorengar@idecnet.com].

Journal de la Société des Américanistes, 2004, 90-1, pp. 183-201. OSociété des Américanistes. 


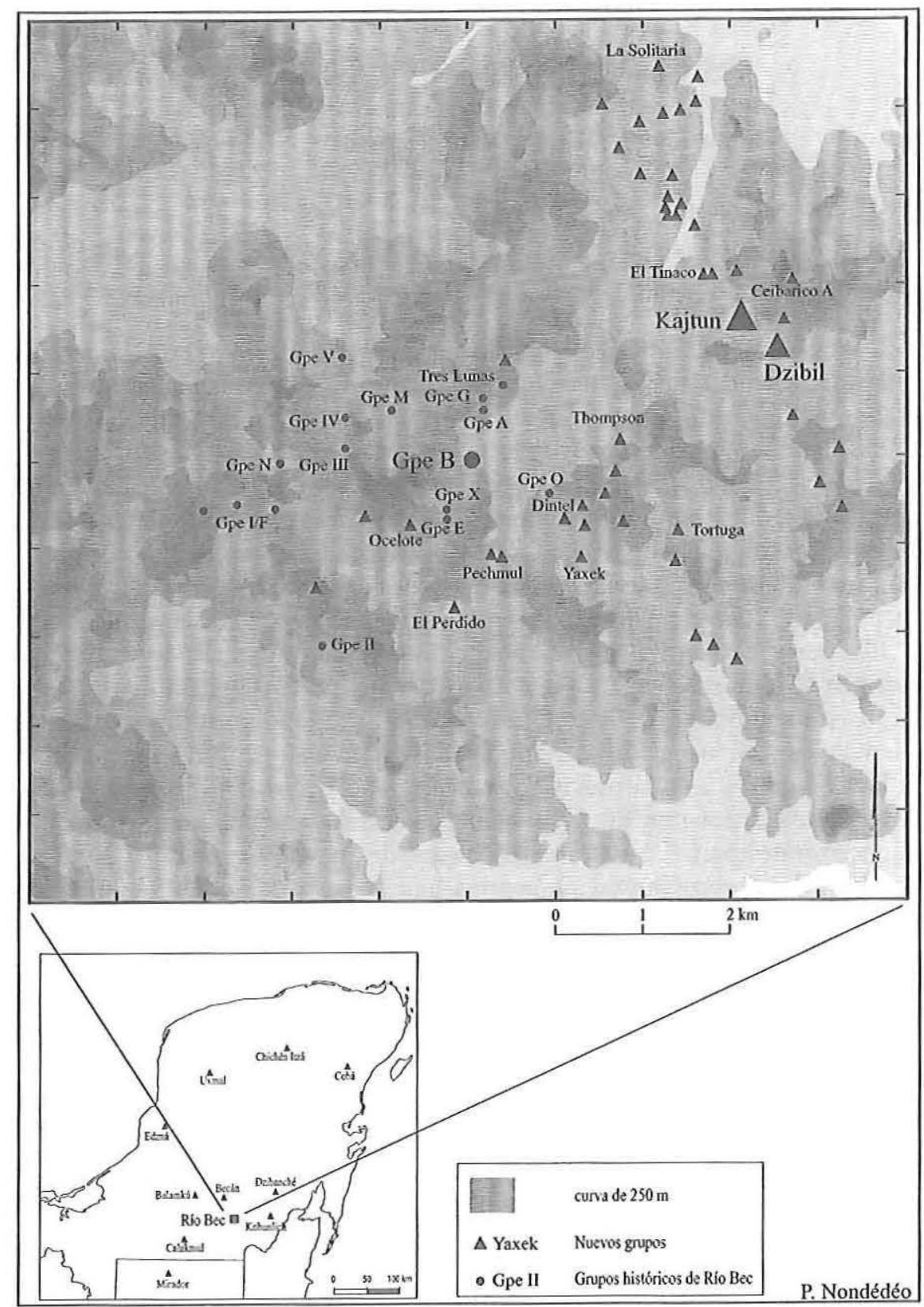

Fig. 1 - Zona de estudio de $100 \mathrm{~km}^{2}$ en la cual se localiza el sitio de Kajtún con respecto al núcleo del « sitio » de Río Bec (Dibujo de Nondédéo) 
históricos de Río Bec. El objetivo central de este reconocimiento regional era de proporcionar al « sitio » de Río Bec un contexto cultural y habitacional así como de definir los límites del asentamiento con respecto a su posible periferia. Este estudio, denominado Operación III del Proyecto Río Bec, abarcó una superficie de $100 \mathrm{~km}^{2}$ (o sea un cuadro de $10 \times 10 \mathrm{~km}$, colocando en su centro la supuesta zona nuclear del « sitio » de Río Bec) y requirió cuatro meses de campo para explorar y registrar los numerosos vestigios descubiertos ${ }^{4}$. Además del sitio de Kajtún, se localizó, por medio de brechas de exploración o con la ayuda de informantes locales, un total de 51 nuevos grupos Río Bec, la mayoría de ellos con restos arquitectónicos e iconográficos notables (Nondédéo s.d.a).

\section{DESCRIPCIÓN DEL SITIO}

El asentamiento principal de Kajtún se encuentra en un sector bastante plano (230 m s.n.m.), en la orilla de un sistema de drenaje S-N atravesado por un arroyo temporal y ocupado por zonas pantanosas (bajos). En sus lados sur, este y norte, el sitio está circonscrito por una serranía angosta donde localizamos algunos grupos «satélites» de Kajtún, entre los cuales cabe mencionar Dzibil, un pequeño conjunto arquitectónico ubicado $500 \mathrm{~m}$ al sureste, donde se descubrieron las estelas 6 y 7 . Kajtún mismo (Figura 2) se compone de un total de más de 62 estructuras dispuestas sobre 6 hectáreas ( $300 \mathrm{~m}$ E-O por $200 \mathrm{~m} \mathrm{~N}$-S). Presenta una forma de organización espacial atípica, en relación tanto al modelo Río Bec como al de la tradición Petén : de la Plaza Principal, ubicada en el extremo oeste, parten dos alineamientos $\mathrm{O}-\mathrm{E}$ de estructuras bajas que circonscriben un espacio central ocupado por una serie de patios y sectores de circulación. Este espacio central queda abierto en su lado este, allí donde se encuentran varias estructuras alargadas. A primera vista, la naturaleza del asentamiento y la distribución de sus estructuras sugieren un desarrollo espacial del sitio en diferentes etapas (dos o más) que podrían haber correspondido a ocupaciones distintas.

La Plaza Principal, de aproximadamente $50 \mathrm{~m}$ de lado, se sitúa sobre una terraza artificial sobreelevada con respecto al nivel natural ${ }^{5}$. Su plano ortogonal, la disposición, el tipo así como el volumen de los edificios que la componen recuerdan un esquema de asentamiento más difundido en la tradición Petén ${ }^{6}$. Consta de siete estructuras y está dominada por la estructura 1, un gran basamento piramidal de $12 \mathrm{~m}$ de alto (1-a), cuyo impacto visual está reforzado por el adosamiento de otros dos basamentos menores en su lado sur (b y c). Con excepción de la estructura 2 - la cual se sitúa en el lado sur de la plaza, alcanza $7 \mathrm{~m}$ de alto y comprendió dos (o más) crujías alargadas -, las demás estructuras que delimitan la plaza tienen un promedio de $2.5 \mathrm{~m}$ de alto y se componen de una sola crujía. Por su parte, el basamento 1-a no muestra evidencias claras de una superestructura, tampoco de una escalera, pero está claramente relacionado con 


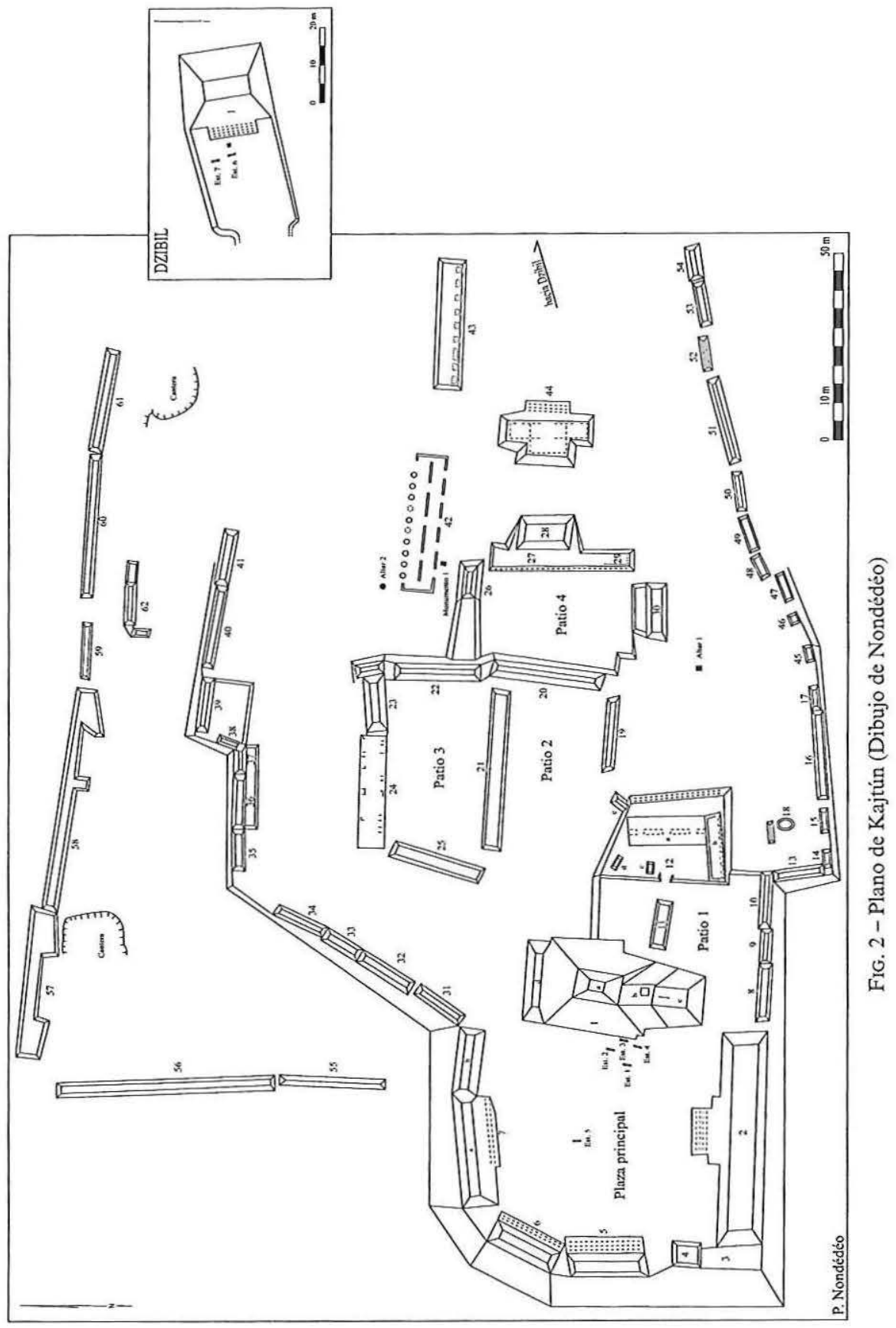


una serie de cuatro estelas esculpidas (Est. 1 a 4) sin altar, que están erigidas a su pie. Esta asociación estela/basamento piramidal, casi inexistente en los sitios Río Bec, es otro elemento característico y esencial de la tradición Petén. Cabe agregar que este patrón se encuentra también en el Grupo Dzibil donde las dos estelas (Est. 6 y 7) se ubican al pie de una estructura piramidal de $8 \mathrm{~m}$ de alto. En cambio, la presencia de una estela lisa ${ }^{7}$ (Est. 5) en el centro de la Plaza Principal de Kajtún, sin relación alguna con un edificio en especial, es algo raro en la tradición Petén : esta posición podría indicar una función distinta para esta estela en comparación con las demás ${ }^{8}$.

A partir de las esquinas NE y SE de la Plaza Principal, sin lugar a dudas el centro político y ritual del sitio por sus edificios y sus estelas, corren hacia el este y sobre una distancia comprendida entre 150 y $200 \mathrm{~m}$, dos alineamientos de estructuras, uno al norte (Estrs. 31 a 41), otro al sur (Estrs. 8 a 54) cuya altura oscila entre 0.4 y $2.5 \mathrm{~m}$. Podrían haber desempeñado (i entre otros ?) un uso residencial, como lo atestigua la presencia de varios metates entre sus escombros. Enmarcan un espacio central ocupado por 3 patios agrupados, y amplios espacios abiertos de circulación. En uno de ellos, localizamos un altar cuadrado, monolítico y liso (Alt. 1), el cual mide $0.97 \times 0.88 \mathrm{~m}$ y $0.39 \mathrm{~m}$ de alto.

\section{Estructuras alargadas}

En términos generales, pocas estructuras de Kajtún presentan huellas de saqueo, con excepción de la estructura 1 que fue afectada superficialmente en dos sectores de su fachada oeste. Los escasos edificios que exponen algunos restos arquitectónicos se concentran principalmente en la parte central del sitio. Indican una influencia Río Bec tanto en el labrado de las piedras como en el sistema constructivo. Entre esos edificios, cabe señalar la presencia de varias estructuras alargadas, las cuales se caracterizan por la presencia de una o dos crujías paralelas y alargadas, sin subdivisión interna y numerosas entradas en su fachada tanto delantera como trasera. De hecho, sus fachadas presentan muros interrumpidos (Estr. 12-a, 42 y 43), pilares de sección cuadrada o rectangular (Estr. 24, 12-b) o bien columnas de mampostería, exentas (Estr. 42). La morfología de estas estructuras, sin espacio privado, impide a priori cualquier uso de carácter habitacional.

Así, la estructura 24, de dos crujías paralelas abovedadas, consiste en un montículo de $29.5 \mathrm{~m}$ de largo por $3.5 \mathrm{~m}$ de alto. Abre, tanto en su lado norte como sur, por pilares de mampostería, revestidos con pequeños paramentos cuadrados finamente labrados, los cuales indican claramente una afiliación arquitectónica Río Bec ${ }^{9}$. Dado el volumen de los escombros en la parte central del montículo, no queda claro si existían vanos de comunicación entre ambas crujías. La estructura 12-b es otro tipo de edificio abierto por pilares : se compone de un solo cuarto alargado, cerrado en tres de sus lados por un muro bajo 
que soportaba un techo de materiales perecederos ${ }^{10}$. Su fachada sur abre por vanos delimitados por cinco pilares rectangulares.

La estructura 42 es, sin lugar a dudas, el mejor ejemplo en Kajtún de estructuras alargadas abiertas con muros interrumpidos. Es un edificio de dos crujías que mide $36.6 \mathrm{~m}$ de largo por $8 \mathrm{~m}$ de ancho. Adopta un sistema muy singular de aperturas, distinto según su fachada. Así, en su lado sur, un muro interrumpido delimita cinco vanos de $2.5 \mathrm{~m}$ de ancho mientras que, en su lado norte, está provisto de una columnata : 10 columnas de mampostería, exentas (de $1 \mathrm{~m}$ de diámetro en promedio) enmarcan 11 accesos. Un muro divisorio interconecta ambas crujías por cinco vanos que no respetan, con excepción del vano central, el eje de las cinco entradas sur. Este edificio, al igual que la estructura anterior, parece haber tenido un techo de materiales perecederos, dada en particular la ausencia de escombros en el interior de las crujías " ${ }^{\text {. }}$.

Aunque se encuentran en mal estado de conservación, las estructuras 12-a y 43 constituyen tipos similares a la estructura 42. La primera consta también de dos crujías alargadas $(20.84 \mathrm{~m})$ separadas por un muro interrumpido por tres vanos. Abre tanto al este como al oeste pero, debido a su alto grado de alteración, no se pudo precisar más su sistema de aperturas. Sabemos que el cuarto oeste abría por un muro interrumpido con, al menos, tres vanos y soportaba un techo de materiales perecederos. En cambio, el cuarto este, que parece haber sido abovedado, no conserva evidencias de su modo de apertura. La misma imprecisión vale para la estructura 43 , otro edificio alargado ( $35 \mathrm{~m}$ por 7.26 de ancho) provisto $\sin$ dudas de un techo de materiales perecederos. Aparentemente, habría constado de una sola crujía delimitada en tres lados por un muro bajo mientras que la fachada sur habría consistido en un muro interrumpido, de 9 macizos y 10 vanos.

El tipo de edificios alargados de dos crujías no parece tener equivalente en los sitios y estructuras Río Bec conocidas hasta la fecha. Si bien existen algunos ejemplos de estructuras abiertas con columnatas, difieren sensiblemente de la estructura 42 de Kajtún en cuanto a su morfología ${ }^{12}$. Asimismo, los escasos ejemplos reportados en la zona Río Bec de edificios provistos de muros interrumpidos o de una galería de pilares en su fachada tampoco se pueden comparar con las estructuras 12-a y 24 de Kajtún ${ }^{13}$. En efecto, constan generalmente de una crujía sencilla, la cual, además, da hacia un solo lado ${ }^{14}$. Esta categoría de edificios, parecida a la estructura 12-b de Kajtún, corresponde en realidad a un tipo de estructura que nace durante el Clásico Tardío y Terminal y se difunde en toda la zona maya. Presenta, por ejemplo, algunas similitudes morfológicas con las estructuras en forma de $\mathrm{C}$ o de « tipo galería » que aparecen en la región Puuc durante el Clásico Terminal (Prem 2003, pp. 291-300), a pesar de la ausencia de la típica banqueta que corre a lo largo de los muros trasero y laterales de los edificios Puuc ${ }^{15}$. Está tambien representada en sitios como Tikal, en particular en la Acrópolis Central (Estr. 5D-67, 5D-72), en Edzná (Juego de Pelota) o en Copán (Estr. 6) ${ }^{16}$. 
Por su parte, el tipo de estructuras de dos crujías abiertas en sus dos lados principales con muros interrumpidos es aún más escaso. Sólo en Dzibanché (Estr. 3 y 4), pudimos encontrar estructuras con una morfología similar a la 42 de Kajtún (Campaña 1997, pp. 57-64). Fechados para el Clásico Tardío, estos edificios constan de dos crujías abovedadas, de $45 \mathrm{~m}$ de largo. Dan hacia el exterior por un muro interrumpido con 9 vanos. Como en el caso de la estructura 42 de Kajtún, las dos crujías comunican entre sí por cinco entradas que no respetan el eje de los vanos exteriores ; sin embargo, y de la misma manera, el vano central del muro divisorio está perfectamente alineado con la entrada central de cada fachada exterior ; pero, a diferencia del edificio de Kajtún, un poco aislado y relativamente bajo, ambas estructuras de Dzibanché descansan sobre un basamento monumental de $8.5 \mathrm{~m}$ de alto y alcanzaban una elevación de $5 \mathrm{~m}$ en su estado original (Campaña ibid.). Además, delimitan los lados norte y sur de la Plaza Principal, lo que claramente sugiere funciones públicas, tal vez ausentes en los edificios de Kajtún.

En la Acropolis Central de Tikal, Harrison (1999, pp. 185-186) observó una categoría de edificios un poco parecida a la estructura 42 de Kajtún. Tomando el ejemplo de la estructura 5D-71, se pueden describir como abiertas en sus dos fachadas por medio de muros interrumpidos pero constan, a veces, de una sola crujía. Son consideradas, con base en su localización y morfología, como edificios-« frontera » que sirvieron para restringir y controlar el acceso desde lugares públicos hacia sectores ceremoniales y/o privados como suelen ser los patios (Harrison ibid. ; Arnauld 2001, pp. 368-371). Esta categoría de edificios de transición se halló también en otros sitios de la región Petén como Caracol y Piedras Negras (Arnauld ibid.) o, más recientemente, en Nakum (Bazy com. pers.). Una función similar se podría tal vez aplicar a las estructuras 3 y 4 de Dzibanché, las cuales, de cierta manera, restringen el acceso a la Plaza Principal. Lo mismo podría haber sucedido con la estructura 24 de Kajtún, si bien existe una interconección entre sus dos crujías. En este caso, habría controlado el acceso al Patio 3. Eso podría haber sido válido también para la estructura 12-a que restringe el acceso al Patio 1 . En cambio, esta función de ninguna manera podría haber existido en el caso de las estructuras 42 y 43 : ambas efectivamente se ubican en lugares de circulación muy abiertos, sin relación clara con otras estructuras, ni con espacios definidos y controlados. En vez de delimitar lugares públicos o privados, estas dos estructuras se sitúan en el centro de un amplio espacio, circonscrito sin embargo, tanto al norte como al sur, por los dos alineamientos de estructuras citados con anterioridad. Dada esta configuración espacial particular, casi paradójica, y si todas las estructuras son bien contemporáneas, habría tal vez que buscar otras funciones que las generalmente propuestas : para actividades administrativas, reuniones, iniciación de jovenes solteros o de guerreros,... (Arnauld ibid., p. 377). 


\section{El Dios Gordo}

Además de su plano original, la estructura 42 de Kajtún es también interesante por su asociación con monumentos muy singulares. Así, en su lado norte, está relacionada con un altar monolítico esférico, de piedra caliza (Alt. $2^{17}$ ) y, en su lado sur; con una escultura exenta, el Monumento 1 (Figura 3). Todavía en su posición vertical original pero bastante erosionado, este monumento se localiza aproximadamente a un metro de la fachada sur del edificio 42. La escultura mide $1.64 \mathrm{~m}$ de alto, tiene una profundidad de $0.47 \mathrm{~m}$ y un ancho que varia entre 0.29 y $0.35 \mathrm{~m}^{18}$. Representa a un personaje parado y de frente, esculpido en altorrelieve, que mira hacia el sur. Su parte trasera, plana, quedó aparentemente sin
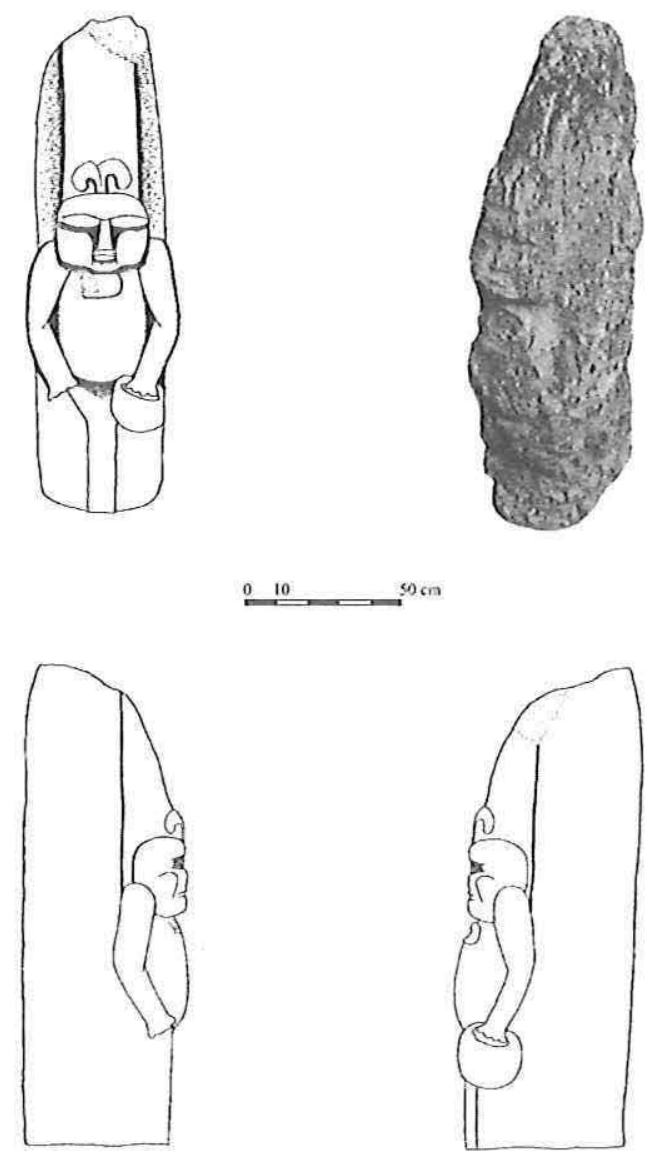

Fig. 3 - Monumento 1 de Kajtún (Dibujos de Patrois) 
inscripción glífica. El personaje ocupa los dos tercios del monumento y está representado de manera muy esquemática : faltan algunos detalles anatómicos tales como las piernas y los pies, las orejas o el cuello. Carece de adornos (collar, pulsera) pero, en vez de un tocado, conserva dos plumas en volutas que nacen directamente de su cráneo. Por fin, lleva en la mano izquierda un objeto erosionado que tiene la forma de una pequeña bolsa.

Según J. Patrois, iconóloga del proyecto Río Bec, con su vientre y sus mejillas prominentes y redondeados, sus ojos globulares y salientes, sus brazos a lo largo del cuerpo y ligeramente doblados hacia el bajo vientre, el personaje del Monumento 1 de Kajtún representa al « Dios Gordo », una entidad bien presente en el arte monumental en piedra de la región Puuc durante el Clásico Terminal ${ }^{19}$. En efecto, esta escultura desarrolla algunos rasgos parecidos a la Columna 2 de la estructura 3C7 de Oxkintok (Pollock 1980, fig. 522, p. 303), la cual está generalmente interpretada como la imagen de un « Dios Gordo ». Además, el personaje de Kajtún posee un pectoral muy erosionado, justo debajo del mentón, el cual podría representar una mano, tal como aparece en el ejemplo de Oxkintok. Sin embargo, representado desnudo con solamente un taparrabo triangular sencillo, este personaje carece del vestido « acolchado » característico de los especímenes del Puuc.

La presencia de este "Dios Gordo » en un sitio tan al sur como Kajtún, parece muy sorprendente y atípica. En efecto, hasta la fecha esta categoría de representaciones en piedra del Clásico Terminal había sido reportada exclusivamente en la región Puuc donde constituía una de las particularidades iconográficas. Incluso, en el Puuc mismo, está presente en un número muy contado de sitios de la región (Oxkintok, Santa Barbara o Dzekilna). Su hallazgo en Kajtún, fuera del contexto geocultural común de este tipo de representación y en un lugar alejado por más de $200 \mathrm{~km}$ de los ejemplos más sureños del Puuc, plantea problemas ¿ Como interpretar su presencia allí ? ¿ Se trata de un elemento más de una influencia tardía del Puuc sobre la región Río Bec o, a la inversa, de un elemento precursor, un intento en gestación en la región Río Bec, difundido hacia el Puuc pero abandonado localmente después ? Tal vez el sondeo que excavamos al pie del monumento nos permita, a partir del material cerámico asociado y de la secuencia estratigráfica, dar una respuesta.

Finalmente, la localización de este monumento al pie de la estructura 42 es otro aspecto muy llamativo. En otros lugares, el « Dios Gordo » aparece bajo la forma de una columna en la entrada de ciertos edificios prestigiosos. Al lado de él, está generalmente representado sobre otra columna un personaje humano ricamente vestido y decorado (Pollock ibid.). Estas columnas desempeñan un papel arquitectónico importante ya que sostienen dinteles y una bóveda. Por su parte, el « Dios Gordo » de Kajtún aparece totalmente exento, sin ninguna relación arquitectónica con los macizos que delimitan los diferentes vanos del edificio 42 . Además, a pesar de varias observaciones meticulosas, aparece aquí solo, sin 
contraparte humana, lo que constituye otra de sus particularidades ${ }^{20}$. Dada su localización, podría en definitiva haber tenido un papel no muy diferente de una estela o de un altar.

\section{DocumentaCión DE LOS MONUNentos GLíficos de KaJTÚN}

En Kajtún fueron registradas ocho esculturas en las temporadas de 2002 y 2003 : cinco estelas (Est. 1 a 5) en la Plaza Principal, el Monumento 1 al pie de la estructura 42 y las dos últimas estelas (Est. 6 y 7) en el Grupo Dzibil (Nondédéo et al. 2002, pp. 7-9 ; Lacadena 2004). Todas las estelas que habían sido encontradas en el sitio durante la primera temporada fueron revisadas en 2003 (Est. 1 a 4 y 6), decidiéndose trabajar con las que estaban en mejor estado, en particular las 1,4 y 6 . Las estelas 2 y 3 de la Plaza Principal se encuentran en muy mal estado de conservación, resultando ilegibles. Sólo la estela 3 podría revelar en el futuro detalles en su parte baja cuando se acometa la limpieza de los escombros de alrededor.

La estela 1 se ubica en la Plaza Principal, al pie de la estructura 1. Permaneció en pie y mide $2,08 \mathrm{~m}$ de alto por $1,12 \mathrm{~m}$ de ancho y $0,65 \mathrm{~m}$ de espesor. Estaba esculpida en tres de sus lados - frontal y laterales - y se encuentra en mal estado de conservación. Su frente conserva elementos de su iconografía en su parte inferior. En su mayor parte, el texto glífico resulta incomprensible por el mal estado en que se encuentra (Figura 4). Se reconocen signos y expresiones aisladas que, por el momento, no ofrecen información coherente, estando pendientes de estudios más profundos. No obstante, destaca la presencia, al final del lado derecho (C6-C7), de la parte final de un nombre, posiblemente

\section{\#-\# CHAN-na CHAHK, ... Chan Chaahk}

con estructura de teónimo - como Tiliiw Chan Chaahk o Muyal Chan Chaahk, nombres de gobernantes atestiguados en el Clásico (Houston y Stuart 1995; Grube 2002) -, seguido de un título (D7). Este título es de suma importancia ya que presenta estructura de Glifo Emblema :

\section{IX-AJAW-li ?}

Dando al numeral IX un valor de B'OLON, el nombre podría transcribirse como

B'olon [i]l Ajaw

« rey de B'olonil » 

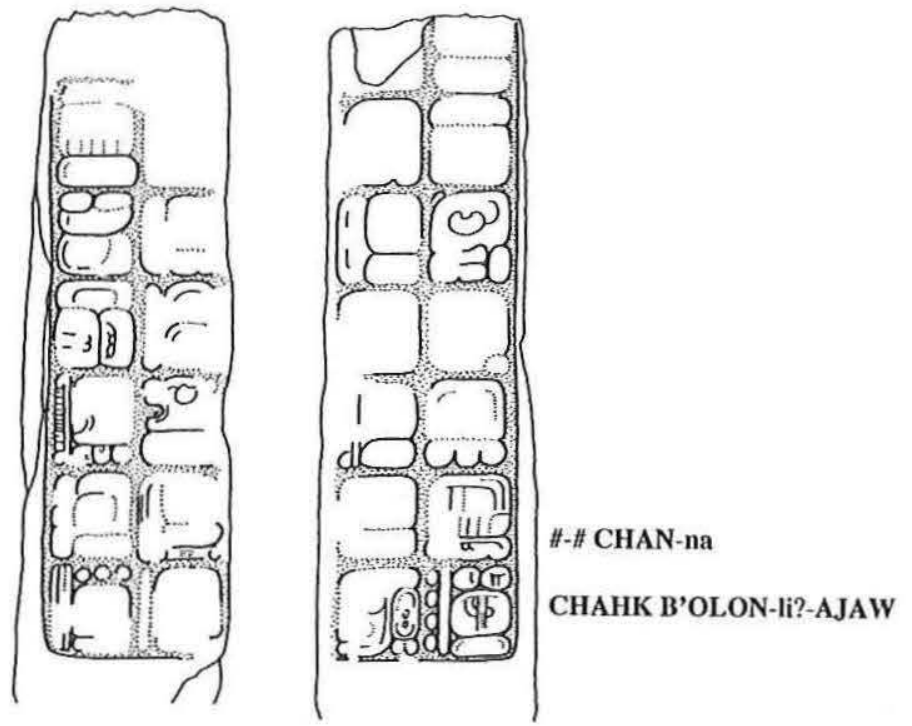

Fig. 4 - Inscripción en la estela 1 de Kajtún (Dibujo de Lacadena)

La estela 4, también en la Plaza Principal, mide 2,10 $\mathrm{m}$ de alto por $1,00 \mathrm{~m}$ de ancho y $0,65 \mathrm{~m}$ de espesor. Caída hacia atrás, la estela ha perdido la mayor parte de su superficie esculpida, produciéndose laminación de la parte frontal, y del lado derecho, expuestos a la intemperie. Ahora muy erosionada, estuvo originalmente esculpida en tres costados - el frente más los laterales. Sólo la columna A del lado izquierdo presenta mejor conservación por haberse quedado parcialmente enterrada (Figura 5). Su inscripción glífica todavía legible consiste esencialmente en una fecha calendárica :

Lado izquierdo :

$\begin{array}{ll}\text { A1 } & \text { IX-B'AKTUN } \\ \text { B1 } & {[X V]^{21}-K ' A T U N} \\ \text { A2 } & \text { mi-HAB' } \\ \text { B2 } & {[\text { [mi]-WINAK-[ki] }} \\ \text { A3 } & \text { mi-K'IN } \\ \text { B3 } & \text { Glifo 10 ?D } \\ \text { A4 } & \text { Glifo 1C } \\ \text { B4 } & \text { Glifo X } \\ \text { A5 } & \text { u-ch'o-[ko]-K'AB'A' } \\ \text { B5 } & {[\ldots]^{22}} \\ \text { A6 } & \text { Ritual de Fuego } \\ \text { B6 } & \text { Ritual de Fuego } \\ \text { A7 } & \text { Ritual de Fuego }\end{array}$




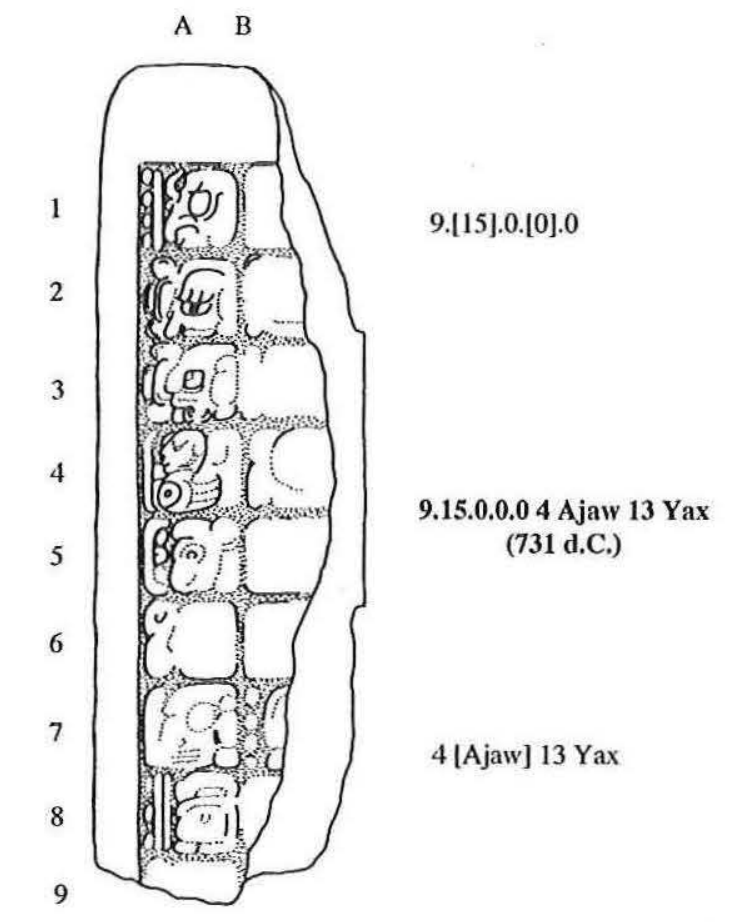

FIG. 5 - Inscripción en la estela 4 de Kajtún (Dibujo de Lacadena)

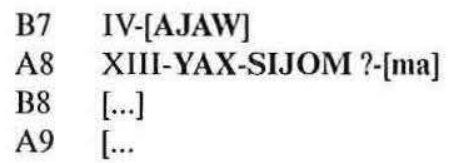

Este monumento recoge pues la fecha de Cuenta Larga de 9.15.0.0.0 4 Ajaw 13 Yax (731 d.C.).

La estela 6 se encuentra en el Grupo Dzibil, al pie de la estructura 1. Mide $2,30 \mathrm{~m}$ de alto por $0,85 \mathrm{~m}$ de ancho y $0,53 \mathrm{~m}$ de espesor. Esculpida en tres costados, y caída hacia atrás, la estela ha perdido por completo su frente esculpido. Su lado derecho está prácticamente borrado, a excepción de unos pocos signos y contornos. En cambio, el lado izquierdo es el que mejor conserva el relieve de los glifos (Figura 6). Como ya advirtió P. Nondédéo (Nondédéo et al. 2002, p. 8), el monumento aún conserva restos de pintura verde y roja en este mismo costado izquierdo. A diferencia de las estelas 1 y 4 que acabamos de comentar, y que presentaban columnas dobles de bloques glíicos en los laterales, la estela 6 ofrece una columna simple de glifos en cada lado. 


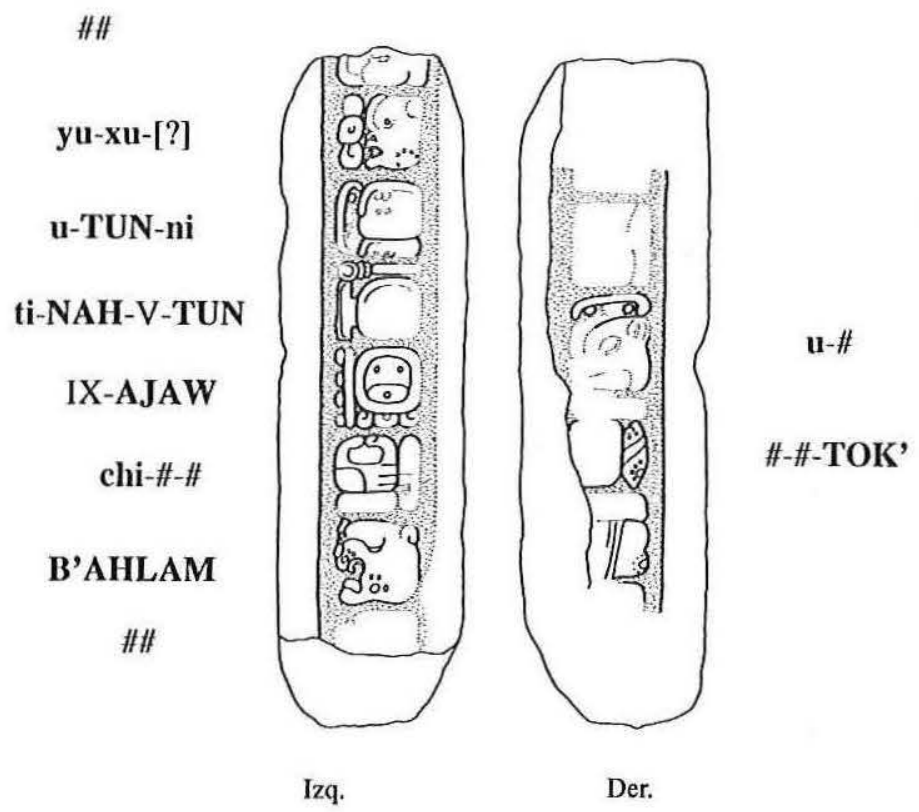

FIG. 6 - Inscripción en la estela 6 de Kajtún, Grupo Dzibil (Dibujo de Lacadena)

Lado izquierdo :

Al [\#-\#] (Glifo Introductor ?)

A2 yu-xu

A3 u-TUN-ni

A4 ti-NAH-V-[TUN]

A5 IX-AJAW

A6 chi-\#-\#

A7 B'AHLAM

A8 $[\ldots]$

Lado derecho :
B1 [...]
B2 $[\ldots]$
B3 $[\ldots]$
B4 u-\#
B5 \#-\#-TOK'
B6 \#-\#-TUN/WITZ/ku?
B7 $[\ldots]$ 
La sintaxis de la estela 6 es inusual, ya que no comienza con la información calendárica, sino que ésta se inserta entre la expresión verbal dedicatoria del monumento y el propietario del mismo. El texto, cuya transcripción sería

... J yux... utuun, ti naah ho'tuun b'olon Ajaw, Chi... B'ahlam [...

se traduciría como

«...] se esculpió la piedra, en el primer ho'tuun de 9 Ajaw, de Chi... B'ahlam [... ».

La fecha, expresada como ti naah ho'tuun b'olon Ajaw « en el primer ho'tuun de 9 Ajaw » corresponde a 9.18.5.0.0 (795 d.C.).

Los títulos del personaje llamado Chi... B'ahlam, que probablemente irían a partir del bloque A8, están desgraciadamente perdidos. Como propietario de la estela, Chi... B'ahlam es posiblemente el señor local del Grupo Dzibil - o de Kajtún - en esta fecha.

En el lado izquierdo se encuentra en el bloque B4 lo que podría ser un glifo de relación entre dos personajes, precedido del pronombre $u$ - « su », « el... de ». Esta expresión vincularía a Chi... B'ahlam con el personaje cuyo nombre comienza en B5, del que sólo puede leerse el final del nombre, \#-\#-TOK', ...Tok'. Por la cercanía de la fecha de este monumento (795 d.C.) con la de la Banca Norte de la estructura 6N2 del Grupo B de Río Bec (805 d.C.) - véase Arnauld y Lacadena en este mismo volumen - es tentador pensar que este ...Tok' mencionado en Dzibil puede ser el mismo Chan B'ohb' Tok' o Kan B'ohb' Tok' mencionado en la Banca Oeste. Por el estado erosionado de la expresión glífica no podemos saber si la relación hacía referencia a parentesco o a subordinación de índole política.

Además del rasgo peculiar antes señalado de la sintaxis del texto, hay que subrayar la presencia de la expresión uxul " escultura, esculpir » en el texto principal de dedicación del monumento, algo también poco común. En las inscripciones de las Tierras Bajas meridionales, uxul se emplea en contextos menores de soportes esculpidos misceláneos o en firmas de escultores, pero es sumamente infrecuente encontrarlo en la expresión de dedicación del texto principal. Este hecho, sin embargo, es común en textos del norte de Yucatán (por ejemplo, en Oxkintok, Uxmal, Cacabbeec, Dzibilchaltún, Xcalumk'in, K'abah o Ek' Balam).

\section{Consideraciones finales}

El hallazgo de Kajtún nos remite al problema de la comprensión de este sector de la región Río Bec. En particular, su relación con los distintos grupos de Río Bec es clave para vislumbrar la organización social y política local durante el Clásico Tardío y Terminal. Los primeros trabajos en Kajtún pusieron de relieve 
una organización espacial del asentamiento muy atípica, con tal vez dos etapas de construcción del sitio. A la Plaza Principal, corazón arquitectónico del sitio, fundado muy probablemente antes de la aparición de los primeros rasgos culturales Río Bec, se habría agregado con el tiempo, la serie de patios y estructuras alargadas que constituyen la extensión este de Kajtún. Estos nuevos edificios, contemporáneos de la mayoría de los grupos Río Bec ubicados alrededor de Kajtún, usan los mismos canones arquitectónicos y sistemas constructivos. Por su parte, la plaza central de Kajtún no sólo no fue abandonada durante el Clásico Tardío, ya que se erigen al menos cuatro de las cinco estelas - siendo la estela 4 fechada para el año 731 -, sino que adquiere todavía más importancia (política) con la presencia, al pie del basamento monumental del edificio 1, de un Glifo Emblema inscrito en la estela 1, desafortunadamente sin fecha asociada legible.

Este Glifo Emblema, el primer registrado en un sitio de la región Río Bec, podría estar relacionado, de cierta manera, con el patrón de asentamiento de Kajtún, nucleado y con una gran densidad de estructuras, algo muy diferente del patrón de los demás grupos Río Bec, disperso y con pocas estructuras. El papel político y administrativo desempeñado tal vez por Kajtún, según su afirmación como máximo poder, podría explicar estas diferencias y otras más, como la presencia de tipos de edificios poco comunes en Río Bec (las estructuras alargadas). Al igual que en los sitios del Petén, el poder en Kajtún se expresa a través de la persona del gobernante, de cuyos nombres dos están mencionados en las estelas 1 y 6 . El tiempo transcurrido de 65 años entre las estelas 4 y 6 podría sugerir una organización dinástica del poder en este lugar.

Por fin, Kajtún podría haber recibido, al final de su ocupación, una influencia del norte de la península de Yucatán, perceptible no sólo a través de la escultura del « Dios Gordo » (¿ originaria del Puuc ?), sino también en los textos escritos, como en el de la estela 6 , donde se aprecian rasgos característicos de las inscripciones del norte de Yucatán (su sintaxis). Este último aspecto, relacionado con la fecha en Cuenta Corta presente en una banqueta policromada del edificio $6 \mathrm{~N} 2$ del Grupo B de Río Bec, viene a añadir nuevos indicios acerca de una posible transformación política, social y lingüística en la región de Río Bec al inicio del Clásico Terminal.

\section{NOTAS}

1. El Proyecto Río Bec está dirigido por Dominique Michelet y Marie-Charlotte Arnauld mientras que Philippe Nondédéo es director de campo. El Proyecto está financiado por el ministère des Affaires étrangères de Francia, el CNRS, SEDESOL a través del Centro INAH Campeche y Empresas Francesas en México (EFM). Recibe también el apoyo logístico de la companía CIMESA (Grupo Solétanche Bachy) y del CEMCA.

2. Durante el mes de marzo de 2004, se efectuaron seis sondeos en Kajtún (dos en la Plaza Principal, dos al pie de la estructura 42 y uno en los Patios 3 y 4 ) así como uno en el Grupo Dzibil. Los datos, tanto estratigráficos como cerámicos, aún están en proceso de análisis. 
3. Hasta la fecha, contabilizamos solamente 33 estelas, localizadas en 8 de los 60 grupos o sitios registrados en la región Río Bec.

4. Dirigida por P. Nondédéo, esta investigación no habría sido posible sin una beca de la Fundación Fyssen, la cual abarcó todo el año 2003, y sin el apoyo del Proyecto Río Bec. Participaron en este trabajo de campo, Julie Patrois, pasante de doctorado de la Universidad de París I Panthéon-Sorbonne, asi como Mirna Sánchez, Brenda Sauri y Alejandro Pérez, pasantes de licenciatura de la Facultad de Ciencias Antropológicas de la Universidad Autónoma de Yucatán.

5. Gracias a los sondeos 7 y 8 , realizados en marzo de 2004, ubicados respectivamente al pie de las estructuras 2 y 1 , sabemos que la Plaza Principal descansa sobre un relleno artificial que va creciendo hacia el oeste conforme va bajando la pendiente natural. Así, el relleno sólo mide $0.68 \mathrm{~m}$ de espesor al pie del basamento 1 pero alcanza más de $2.29 \mathrm{~m}$ al pie de la estructura 2. Posiblemente, un sondeo al pie de la estructura 5 alcanzaría una profundidad aún superior.

6. En el fondo del sondeo 7, se encontró una plataforma, totalmente cubierta por el relleno de la Plaza Principal. Según Sara Dzul, cerámista del proyecto Río Bec, esta plataforma está claramente asociada con tepalcates de tradición Petén, del Preclásico Medio y Tardío. Se trataría, pues, del sector más antiguo del sitio.

7. La estela 5 es fragmentaria ; mide $0.84 \mathrm{~m}$ de largo, $0.62 \mathrm{~m}$ de ancho y $0.30 \mathrm{~m}$ de espesor.

8. La colocación de una estela lisa en el centro de una plaza, como si fuera un altar, existe en sitios de tradición Río Bec ubicados en la periferia de la región de este mismo nombre : aparece en Nadzca'an, al oeste (Est. 21, Plaza 2, Grupo Bec), o en Pechal, al norte (Est. 5) (Pescador 1998, p. 173; Ruppert y Denison 1943, pl. 74). En el caso de Pechal, la localización de las 5 estelas es similar a la de Kajtún.

9. Los pilares miden un promedio de $1.40 \mathrm{~m}$ de largo (E-0) por $1.10 \mathrm{~m}$ de ancho (N-S). Entre algunos pilares, detectamos la presencia de sillares Río Bec cuadrados de gran tamaño $(0.40 \times 0.40 \mathrm{~m})$ que sirven generalmente para revestir las fachadas. En este caso, indicarían el posible tapiamiento de varios vanos, tal vez para reforzar la bóveda.

10. La altura actual de los muros, inferior a un metro, y la depresión en el centro de la crujía indican la ausencia de una bóveda de mampostería.

11. La parte interior de cada crujía donde, lógicamente, deberíamos encontrar los escombros de una bóveda de mampostería, consiste, en realidad, en una depresión donde resaltan los amontonamientos de sillares que corresponden a cada sección del muro interrumpido. Otro argumento a favor de un techo de materiales perecederos, es que la pared de la fachada sur se eleva sólo $0.50 \mathrm{~m}$ en tanto que el muro divisorio alcanza $1.5 \mathrm{~m}$ de alto.

12. Registramos tres ejemplos de edificios con columnata : la estructura II de Hormiguero (Bueno et al. 1985), la estructura VIII de Becán (Bueno 1999) y la estructura 1 de El Perdido (Nondédéo s.d.b). Los dos primeros ejemplos corresponden a edificios con torres en tanto que el último es una estructura con cuartos múltiples sobre un basamento monumental. El uso y la ubicación de la columnata varian mucho según los edificios. Así, en los dos últimos casos, la columnata se encuentra en la fachada anterior y permite el acceso a los cuartos centrales mientras que, en el caso de Hormiguero, la columnata consiste en un pórtico que corre paralelo al muro de la fachada posterior. Estos tres edificios con columnata, según sus planos y la distribución espacial de sus cuartos, parecen haber desempeñado funciones distintas a las que podrían imaginarse para las estructuras alargadas de Kajtún.

13. Estructura D2 de Kohunlich (Nalda et al. 1997, fig. 19) ; estructura 29 de Nadzca'an (Pescador 1998, p. 177) ; estructura XI de Dzibanché (Campaña 1997, fig. 82.).

14. Es importante subrayar que los ejemplos citados para ilustrar este tipo de edificios alargados no proceden de la zona nuclear Río Bec sino de su periferia donde las influencias estilísticas Rio Bec fueron aparentemente mezcladas con una fuerte tradición local, heredada de la tradición Petén. Algunos autores califican de estilo « híbrido » esta combinación de rasgos arquitectónicos distintos (Nalda y Velázquez 1997). Si nos referimos ahora a la zona nuclear Río Bec, no pudimos identificar edificios alargados con galeria de pilares, a pesar de la presencia de este elemento arquitectónico en algunas construcciones. Asi, en casos como la estructura 1 de Becán (Andrews 1995, fig. 2, p. 84), la estructura 1 de MR2 (Nondédéo 2003, fig. 131), la estructura 1 de La Tortuga (Nondédéo 2004, fig. III-48) 
o la estructura 1 de Tigre Triste (Gendrop et al. 1985), los pilares van generalmente en pares y adornan las fachadas tanto principales como laterales de edificios con cuartos múltiples o bien con torres.

15. La estructura XI de Dzibanché (Campaña 1997, fig. 82), pese a que sufrió algunas modificaciones tardias, parece haber tenido, en su estado original, una banqueta similar a las estructuras en forma de $\mathrm{C}$ del Puuc.

16. Harrison 1999 ; Benavides 1997, pp. 70-71. En Tikal, corresponde a la categoría 4 de Harrison (Arnauld 2001, p. 370, fig. 3).

17. Ligeramente irregular, este altar esférico mide entre 0.75 y $0.80 \mathrm{~m}$ de diámetro.

18. En 2004, excavamos un sondeo estratigráfico al pie del monumento con el fin de liberar su base, conseguir sus medidas completas y establecer la relación con la estructura 42. Los datos recogidos están todavía en proceso de análisis.

19. El epigrafista A. Lacadena fue el quien primero identificó los rasgos del « Dios Gordo » en su visita de 2003. El estudio iconográfico del monumento, el cual confirmó la identificación, se llevó a cabo en 2004 y fue a cargo de J. Patrois. Los datos que se presentan del monumento proceden de su análisis preliminar.

20. No podemos excluir la posibilidad de que el monumento haya sido desplazado de su lugar original y colocado en una segunda etapa al pie de la estructura 42. En este caso, la contraparte humana del « Dios Gordo » se podría tal vez encontrar en otro edificio. En todo caso, este « Dios Gordo " parece haber sido el objeto de un tratamiento especial, pues encontramos, al pie de la escultura y dispuesto entre los escombros de la estructura 42, un depósito fechado por Sara Dzul del Postclásico Tardio.

21. El numeral 15 es reconstruido a partir de los otros elementos de la Serie Inicial y la Rueda calendárica. El contorno del numeral, recto, apunta a una barra, por lo que las posibilidades eran de 5 , 10 ó 15.

22. Este Bloque B5 está completamente perdido, pero correspondería al Glifo A de la Serie Lunar, posiblemente $10 \mathrm{~A}$.

\section{BIBLIOGRAFÍA}

\section{ANDREwS G. F.}

1995 "Structure IV, Becan, Campeche : form, organization and function », in Memorias del segundo congreso internacional de mayistas, IIF, UNAM, México, D.F., pp. 82-116.

ARnauld M.-C.

2001 "La "casa grande" : evolución de la arquitectura del poder del Clásico al Postclásico », in A. Ciudad Ruiz, M. J. Iglesia Ponce de León y M. del C. Martínez Martínez, Reconstruyendo la ciudad maya : el urbanismo en las sociedades antiguas, Sociedad española de estudios mayas, Madrid, pp. 362-401, coll. « Publicaciones de la SEEM » 6.

Benavides Castillo A.

1997 Edzná : una ciudad prehispánica de Campeche. Edzná : a Pre-Columbian city in Campeche, Serie Arqueología de Mexico, INAH/University of Pittsburgh, México, D.F.

Bueno Cano R.

1999 Entre un río de robles, un acercamiento a la arqueología de la región Río Bec, INAH, México, D.F., coll. « Científica » 411. 
Bueno Cano R., R. Yoma, L. A. Martos, A. Pascual y L. Gutierrez

1985 Informe de la temporada 1984 en Hormiguero, Campeche, Archivo técnico del Consejo de arqueología, INAH, México, D.F.

Campaña Valenzuela L. E.

1997 Excavaciones en el Grupo Principal de Dzibanché, Quintana Roo, 1993-1994. Informe del Proyecto arqueológico Sur de Quintana Roo, Archivo técnico del Consejo de arqueología, INAH, México, D.F.

GENDROP P.

1983 Los estilos Río Bec, Chenes y Puuc en la arquitectura maya, UNAM, México, D.F..

Gendrop P., V. Rivera, J. A. Siller y A. Villalobos

1985 "Tigre triste, un sitio recientemente descubierto en la región de Río Bec », Cuadernos de arquitectura mesoamericana, 5, pp. 25-34.

\section{Grube N.}

2002 "Onomástica de los gobernantes mayas », in V. Tiesler, R. Cobos y M. Greene Robertson, eds, La organización social entre los mayas prehispánicos, coloniales y modernos. Memoria de la tercera mesa redonda de Palenque, CONACULTA/ INAH, México, vol. 2, pp. 321-353.

HARRISON P.

1999 The lords of Tikal : rulers of an ancient Maya city, Thames and Hudson, London.

Houston S. y D. STUART

1995 "Of gods, glyphs and kings : divinity and rulership among the Classic Maya ", Antiquity, 70, pp. 289-312.

\section{LACADENA A.}

2004 "Operación VIIB : estudios epigráficos », in D. Michelet et al., Río Bec (Campeche, Mexico) : informe de la segunda temporada del 27 de enero al 25 de mayo de 2003, Consejo de arqueología, INAH, México, D.F., pp. 1-11.

Nalda E. y A. VelázQuez

1997 « De casas, templos y palacios. Notas sobre el asentamiento prehispánico de Kohunlich, Quintana Roo ", comunicación presentada en el IV Coloquio de arqueología Pedro Bosch Gimpera, 28 de noviembre de 1997, IIA, UNAM, México, D.F.

Nalda E., A. Velázquez, S. Balanzario y A. Maciel

1997 Proyecto arqueológico Sur de Quintana Roo 1993-1994, 6 vol., Consejo de arqueología, INAH, México, D.F.

NONDÉDÉO P.

2003 L'Évolution des sites mayas du Sud de l'État du Campeche, Mexique, Archaeopress, Oxford, coll. « British Archaeological Reports, International serie 1171/ Paris monographs in American archaeology » 12.

2004 «Operación III : Reconocimiento micro-regional », in D. Michelet et al., Río Bec (Campeche, México) : informe de la segunda temporada del 27 de enero al 25 de mayo de 2003, Consejo de arqueología, INAH, México, D.F., pp. 1-74.

s.d.a "¿ Existe el "sitio" de Río Bec ? Nuevos datos sobre el patrón de asentamiento de esta zona arqueológica ", Ponencia presentada en el XIII Encuentro Interna- 
cional, Los Investigadores de la Cultura Maya, 11-15 de noviembre de 2003, Campeche [en prensa].

s.d.b "Operación III : Reconocimiento micro-regional », en D. Michelet et al., Río Bec (Campeche, México) : Informe de la tercera temporada del 16 de febrero al 15 de mayo de 2004, Consejo de arqueología, INAH, México, D.F. [en preparación].

Nondédéo P., D. Michelet, M.-C. Arnauld, E. Taladoire, J. Patrois y R. Barrois

2002 Proyecto Rio Bec (Campeche, México) : Informe de la primera temporada del 15 de febrero al 18 de mayo de 2002, Consejo de arqueología, INAH, México, D.F.

2003 "Río Bec: primeros pasos de una nueva investigación », Mexicon, XXV (4), pp. 100-105.

Pescador Cantón L.

1998 « Nadzca’an », Journal de la Société des Américanistes, 84 (1), pp. 167-182.

Pollock H. E. D.

1980 The Puuc: an architectural survey of the hill country of Yucatan and northern Campeche, Mexico, Harvard University, Cambridge, Mass., coll. « Memoirs of the Peabody Museum of Archaeology and Ethnology » 19.

Prem H. J.

2003 "Aspectos de los patrones de asentamiento en la región Puuc central », in H. J. Prem, ed., Escondido en la selva, pp. 273-308, Universidad de Bonn/INAH, México, D.F., coll. « Obra Diversa ».

RUPPERT K. y J. H. DENISON Jr.

1943 Archaeological reconnaissance in Campeche, Quintana Roo and Peten, Carnegie Institution of Washington, Publication 543, Washington, D.C. 